\title{
Tread Profile of Wheel Pair Support Unit
}

\author{
Valeriy Shiler, Alexander Shiler, Alexander Lyubchenko
}
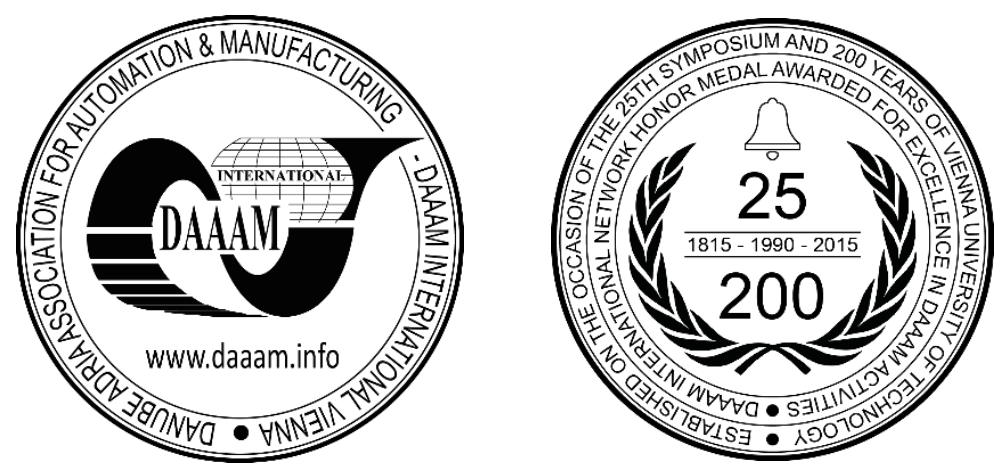

This Publication has to be referred as: Shiler, V[aleriy]; Shiler, A[lexander] \& Lyubchenko, A[lexander] (2016). Tread Profile of Wheel Pair Support Unit, Proceedings of the 27th DAAAM International Symposium, pp.0892-0895, B. Katalinic (Ed.), Published by DAAAM International, ISBN 978-3-902734-08-2, ISSN 1726-9679, Vienna, Austria DOI: $10.2507 / 27$ th.daaam.proceedings. 128

\begin{abstract}
One of the reasons of contact-fatigue damages generation on the tread of the standard wheel pair is the spurious wheel slippage along rails while moving. The spurious slippage makes an additional stress in metal of the wheel in the area of contact region "wheel-rail" and increased wear of the tread. The objective of our research is the development of an engineering solution aimed at the reduction of the metal stressed condition in the area of contact region "wheel-rail". In order to reach the formulated objective, the following tasks were solved: a novel block construction of the wheel set was developed with the main feature, which is an independent rotation of the tread of support unit wheels (leading and supporting) contacting with surfaces of track rail; a novel lateral tread profile of supporting wheel was designed and justified. The research had been carried out using the methods of simulation and physical modeling.

We have got and developed new lateral tread profile of wheel pair support unit, which ensures constant single-point contact of wheel with rail and guarantees the lack of spurious wheel slippage along a rail. Therefore, the corresponding shear stress at the contact point of "wheel-rail" is also lacking. This approach resulted in significant reduction of the metal stressed condition of the supporting wheel in the area of contact region "wheel-rail".
\end{abstract}

Keywords: lateral profile; tread; wheel slippage; stress.

\section{Introduction}

Rail transport leans on the standard wheel pairs, which consist of two wheels immovably mounted on the axle. Possessing equal angular velocity, wheel contacting surfaces with rails (three surfaces) have different values of tread radius. Therefore, movement of the wheel set is accompanied with spurious slippage along the rails, which is a source of: auto-oscillation of wheel set (nosing motion) while moving, increased resistance to movement depending on the square of progressive motion velocity etc. As a result of increased axial load, weight of a train and speed of motion, the wear rate of wheels and rails increased greatly. For example, if 15-20 years ago metal technological exit of wheel bandage amounted to $30-35 \%$ of their total mass, then nowadays this measure reaches $75-80 \%$. At present, greasing (lubrication) of wheels and rail contacting surfaces is widely utilized for wear reduction [1-3]. This approach decreases the rate of deterioration processes, but it does not eliminate their reasons. Therefore, it is considered that any even compromise solution towards tread lateral profile of wheel is positive [2, 3]. For a solution of the problem of deterioration in "wheelrail" system, the authors went by means of the improvement of the whole wheel set construction. 


\section{Problem definition}

For a solution of the problem of dynamic interaction of wheel pair and rail gauge, the authors have proposed a block construction of the wheel set, which main feature is an independent rotation all surfaces their wheels contacting with surfaces of track rail. Besides, new lateral tread profile for the supporting wheel was developed. These technical solutions allowed realization of block wheel pair movement along rails without spurious slippage and lack of auto-oscillation mode (nosing motion), which are inherent in the standard wheel set.

In the presented work, the task of the estimation of influence of new technological solutions on internal metal stress of the supporting wheel of block wheel pair in the area of its contact with surface of rail.

\section{Theory}

First, consider the wheel deterioration model of the standard wheel pair [3], which is presented in Fig. 1. Lateral tread profiles of wheel and rail functionally are divided into the following three areas: A, B and C (Fig. 1). In area (A), contact stresses and lateral slippage are the lowest of all possible values that creates favorable conditions for stability of equipage movement. Contact area (B) is small, and the contact is characterized by extremely difficult stressed condition of wheel material. There are three possible variants of the contact of wheel of the standard wheel pair with a rail: single-point; double-point and conformal contact [3].

Single-point contact inflicts the greatest damages on the wheel and rail. Double-point is inherent in intense slippage and wear, which results in occurrence of material plastic flow on the wheel tread. Conformal comber contact appears to the extent deterioration of working wheel fillet up to the general profile [3-5], and has a number of advantages: contact area rises and specific pressure decreases. It is significant that for the standard wheel pair in running-out mode for all contact areas (A, B, C) and variants of contacting, the slippage is spurious conditioned by peculiarities of the standard wheel pair construction.

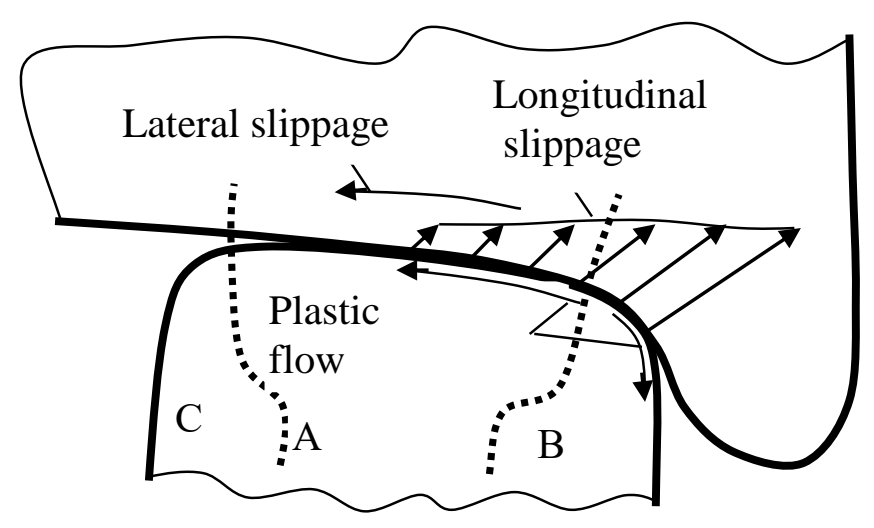

Fig. 1. Constant deterioration model of standard wheel

New construction of the wheel [6, 7], presented in Fig. 2, with working name "wheel unit" consists of leading wheel 1 and supporting wheel 2 , which rotate independently of one another on wheel set axle

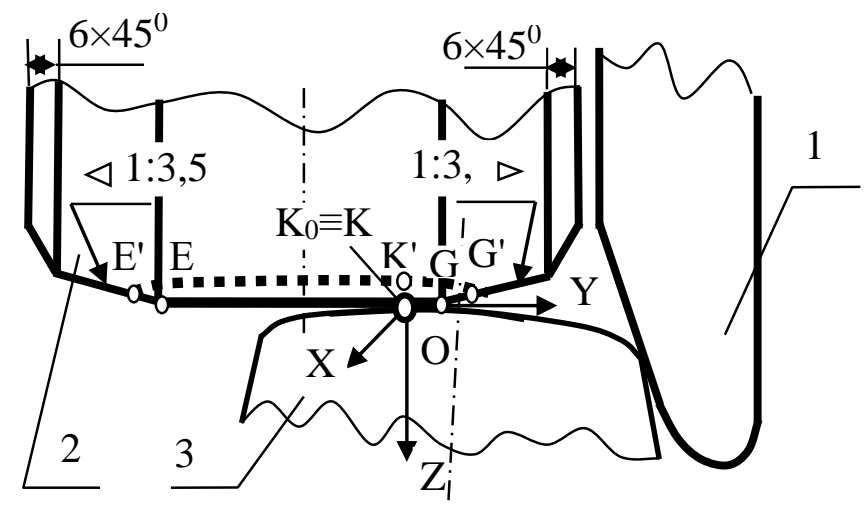

Fig. 2. Lateral profile of wheel treads of support unit 
With accordance to the existed requirements for making lateral tread profiles and structural features of wheel unit, the lateral profile for supporting wheel is developed and is marked with "2" in Fig. 2. The proposed profile is made up of 5 surfaces. Central part of the lateral profile (segment EG) has cylindrical surface. Extreme sections of the profile have equal delineation in the form of two pairs of conic surfaces, which have the following dimensions: $\triangleleft 1: 3,5$ and $6 \times 45^{0}$. These cones have the same purpose that the standard lateral profiles have. In exploitation, the central cylindrical part of the lateral tread profile (segment $\mathrm{EK}_{0}^{\prime} \mathrm{G}$ ) is extended and comes out on adjacent conic surfaces (segment $\mathrm{EE}^{\prime}$ и $\mathrm{GG}^{\prime}$ ). Thus, delineation stability of the cylindrical part is maintained.

Models and experimental data devoted to the research the characteristics of "wheel-rail" system and presented in proceedings of foreign authors [8-10] are directed on the analysis of multibody systems. In this work, comparative calculations for the supporting and standard wheels were implemented for the objective of contact material stresses estimation in "wheel-rail" system. For each construction of the wheels, extreme conditions of contacting with rail head were accepted: for standard wheel - outworn tread profile and single-point contact with rail; for wheel unit - new linear profiles of the supporting and leading wheels and corresponding to them single-point contacts.

For normal problem solution the Hertz contact theory was applied [3]. Stresses at contact point lying on the pressure axle at a depth on $\mathrm{O}_{\mathrm{K}} \mathrm{Z}$ axis are equal to [3]:

$$
\begin{aligned}
& \sigma_{x}=-\left[\frac{a^{2}+2 z^{2}}{a \sqrt{a^{2}+z^{2}}}-\frac{2 z}{a}\right] q_{0} \\
& \sigma_{z}=-\frac{a}{\sqrt{a^{2}+z^{2}} q_{0}} \\
& \sigma_{y}=\mu\left(\sigma_{x}+\sigma_{z}\right)=-2 \mu \frac{\sqrt{a^{2}+z^{2}}-z}{a} q_{0} \\
& \tau_{x z}=0
\end{aligned}
$$

where $\sigma_{X}$ and $\sigma_{Z}$ are the main normal stresses operating at the areas, which are perpendicular to $\mathrm{O}_{K} \mathrm{X}$ and $\mathrm{O}_{K} \mathrm{Z}$ axis; are main stresses operating at the areas lying in plane of tread cross-section; $\mu$ is the Poisson ratio.

The largest shear stress from normal load in plane XOZ (Fig. 2) is defined as follows:

$$
\tau_{\max }=\frac{\sigma_{x}-\sigma_{z}}{2}=\frac{z}{a}\left[1-\frac{z}{\sqrt{a^{2}+z^{2}}}\right] q_{0}
$$

Along with vertical load in horizontal plane of "wheel-rail" contact of the standard wheel, spurious friction forces of slippage have an effect, which make longitudinal and lateral stress components at the "wheel-rail" contact point. On the basis of the theory of independency of force effect, the contact stresses are summed up in equivalent stress [3].

\section{Experimental Results}

We have obtained that, according to the calculation results and the Hertz theory, maximum static stress of the grip occurs on the wheel tread, and maximum shear stress is at a depth of 2.0-4.0 mm. If normal deformation on the contact surface has elastic nature, then plastic deformations can appear under contact surface in the area of the maximum shear stresses.

When a wheel passes along a rail, repeated stress grip-strain occurs under contact area surface. The stress leads to accumulation of subsurface plastic deformation and origination of residual stresses in material [3], which are casual for various types of contact-fatigue damages on the tread of wheel and rail. When tangential force (for example, spurious slippage) is applied to the contact area, maximum shear stress rises and displaces closer to the tread. Further increase of the tangential force can result in appearance of alone region of potential damage of the material [3].

\section{Discussion of Results}

For demonstration of shear stress influence on contact bearing capacity (for example, due to spurious slippage), the so-called Johnson adaptability diagram (Fig. 3) is used. In this diagram, the border (line 1) between regions of different material behavior as a dependency of loading factor $\mathrm{q} 0 /[\tau]$ on coefficient $\mu=\mathrm{T} / \mathrm{N}$, where $\mathrm{q} 0$ is the normal contact pressure, $[\tau]$ is the yield point of material, $\mathrm{T}$ is the tangential force and $\mathrm{N}$ is the normal force. The largest level of plastic flow is reached on the contact surface if calculation results are above the curve 1 (Fig. 3). 


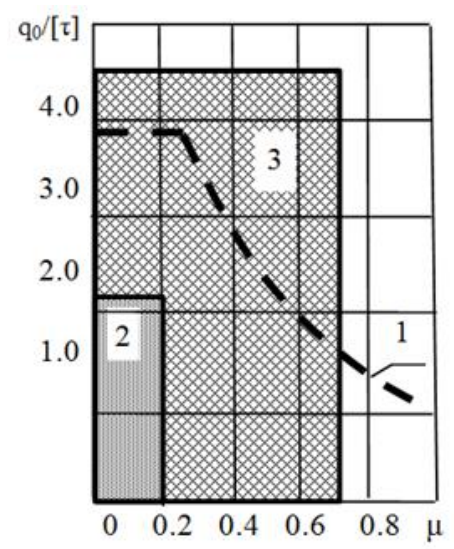

Fig. 3. Adaptability diagram of wheel material.

In accordance with the diagram in Fig. 3, in the interval of the accepted parameters of "wheel-rail" system, the stressed possible conditions of the material of the wheel pair support unit (area 2) are significantly less (in 2-3 times) in compassion with the standard wheel (area 3).

\section{Conclusion}

1. The proposed lateral cylindrical tread profile of wheel pair support unit ensures single-point of the supporting wheel with rail head in wheel unit position relative to track rail.

2. In process of forward movement, the supporting wheel rolls along a rail in the pure rolling mode without spurious slippage thanks to the independent rotation and cylindrical surface.

3. Lack of the spurious slippage reduces in 2-3 times the stressed wheel metal condition in the contact area of wheel and rail and brings to the minimum of their tread wear.

Thus, for the contact stresses, the block construction of wheel pair with cylindrical central part of the supporting wheel tread ensures conditions for the increase of axial load and motion speed of rolling stock for the existed railroad track architecture and improvement of operation safety.

\section{References}

[1] V.M. Bogdanov, "Reduction of deterioration rate of wheel flange and rail lateral deterioration," Railways of the world, vol. 12, 1992, pp. 30-34

[2] Zhiguo Li, Qing He, "Predicting failure times of railcar wheels and trucks by using wayside detector signals," IEEE International Conference on Mechatronics and Automation, 2014, IEEE, pp. 1113-1118. (DOI: 10.1109/ICMA.2014.6885854)

[3] W.J. Harris, S.M. Zakharov, J. Lundgren, H. Tournay, W. Ebersöhn, "Guidelines to best practices for heavy haul railway operations: wheel and rail interface issues," Virginia Beach, International Heavy Haul Association Publ., 2001. 408 p.

[4] I.V. Kragelsky, N.B. Demkin, “Contact area of rough surface,” Wear, 1960, vol. 3, iss. 3, pp.170-187. (DOI: 10.1016/0043-1648(60)90136-8)

[5] N.B. Demkin, V.V. Izmailov, "Surface topography and properties of frictional contactsSurface topography and properties of frictional contactsSurface topography and properties of frictional contacts," Tribology International, 1991, vol. 24, Iss. 1, pp. 21-24. (DOI: 10.1016/0301-679X(91)90058-H)

[6] Patent Num.2011 154293 (RF) MKI V60V 9/1 (2006.01) Tread lateral profile cushioned wheel bandage of wheel set, Shiler V.V., Shiler A.N. Application: 2011154293/11 from 28.12.2011. Applicant Shiler V.V. Published vBI, 10.07.2013 Bulletin Num. 18

[7] A. Shiler, "Analysis and simulation of new wheel pair construction," Procedia Engineering, 2015, vol. 100, Elsevier, pp. 1714-1723. (DOI: 10.1016/j.proeng.2015.01.547)

[8] A. Rovira, A. Roda, M.B. Marshallb, H. Brunskill, R. Lewis, "Experimental and numerical modelling of wheelrail contact and wear," Wear, 2011, vol. 271, Elsevier, pp. 911-924. (DOI: 10.1016/j.wear.2011.03.024)

[9] S. Magheri, M. Malvezzi, E. Meli, A. Rindi, "An innovative wheel-rail contact model for multibody applications," Wear, 2011, vol. 271, Elsevier, pp. 462-471. (DOI: 10.1016/j.wear.2010.10.038)

[10] M. Mahdi Jalilia, H. Salehi, "Wheel/rail contact model for rail vehicle dynamics," ComptesRendusMecanique, 2011, vol. 339, Elsevier, pp. 700-707. (DOI: 10.1016/j.crme.2011.07.006) 